\title{
BANCA Y CRISIS ECONÓMICA \\ EN ESPAÑA, 1930-1935: UN NUEVO ENFOQUE
}

JOSÉ LUIS GARCIAA RUIZ

Universidad Complutense

\section{RESUMEN}

La historia económica de la Segunda Repúlica española ha recibido un gran empuje en los últimos años, gracias a la publicación de numerosos trabajos, cuyos resultados, sin embargo, han sido contradictorios. En este trabajo se pretende hacer una aproximación al comportamiento de la banca privada española entre 1930 y 1935 desde las nuevas teorias económicas del racionamiento del crédito. Las conclusiones tienden a apoyar una explicación de oferta para la caida del volumen de crédito que tuvo lugar.

\section{ABSTRACT}

The economic history of the Spanish Second Republic has received a big impulse in the last years, but new research is still required. In the present work we approach the behaviour of the Spanish banking system between 1930 and 1935 on the basis of the new theories on credit rationing. The conclusions support a supply side interpretation of the fall in the avalaible amount of credit.

\section{INTRODUCCIÓN}

Tras la aparición de un breve pero influyente trabajo de Sardà se tendió a caracterizar el comportamiento de los factores monetarios durante la Segunda

\footnotetext{
'Quisiera agradecer las muy utiles recomendaciones que he recibido de los profesores $\mathrm{Pa}$. blo Martin Aceña y Francisco Comin en la elaboración de este articulo, asi como las de dos lectores árbitros anonimos. Este articulo intenta resumir mi tesis doctoral, que fue dirigida por el
} 
República española como deflacionista y depresivo 2. Con posterioridad, muchos otros autores abundaron en esta opinión '. Sin embargo, recientemente, nuevas investigaciones han venido a cuestionar con mayor rigor la política monetaria desarrollada durante ese periodo, y concluyen que es preferible explicar la caida registrada en el crédito por la debilidad de la demanda 4.

El presente trabajo es un intento de contrastar si las nuevas aportaciones teóricas sobre el comportamiento del crédito pueden arrojar luz en esta polémica, como ya lo han hecho a la hora de explicar lo ocurrido en Estados Unidos durante la Gran Depresión. Empezaremos exponiendo las bases de este enfoque teórico (Sección II), para después caracterizar el sistema crediticio español de la década de 1930 (Sección III), y, finalmente, tratar de realizar una aplicación del nuevo enfoque a este caso (Sección IV). Acabaremos exponiendo algunas conclusiones.

\section{MERCADOS FINANCIEROS Y RACIONAMIENTO DEL CRÉDITO}

Existe un cierto consenso en la idea de que los modelos macroeconómicos tradicionales han tendido a simplificar en exceso el papel del crédito bancario s. A pesar de la complejidad y sofisticación que tienen los mercados mone. tarios y financieros, se ha tendido siempre a representarlos por sólo dos variables: la oferta monetaria y los tipos de interés. Además, a la oferta monetaria se le ha otorgado todo el protagonismo a la hora de explicar las interacciones existentes entre el sector monetario y el sector real de la economía. Sin embargo, cada vez resulta más evidente que el desconocimiento de la influencia en la tasa de inversión de las decisiones que los bancos toman sobre la composición de sus activos ha impedido hasta ahora estudiar adecuadamente estas relaciones.

Cabe advertir que algunas consideraciones sobre las consecuencias de fijar los tipos de interés crediticios por encima o por debajo de su nivel de equilibrio fueron ya hechas por Adam Smith en el capitulo IV de The Wealth of the

profesor Juan Hernández Andreu. Naturalmente, soy responsable único de todos los errores que puedan haberse cometido.

2 Sarda (1970).

1 Veanse Balcells (1971), Tortella y Bustelo (1976), Nadal y Fontana (1978), Eguidazu (1978) y Hernández Andreu (1980 y 1986).

+ Asi, por ejemplo, Tortella y Palafox (1982) y Martin Aceña (1984).

'Véase, por ejemplo, Vega (1992), p. 7. 
Nations, y qué referencias dispersas (pero desaprovechadas) sobre la problemática del crédito fueron apuntadas desde entonces hasta finales de la década de $1960^{\circ}$. Sin embargo, sólo hace veinte años que empezó a formarse un nuevo cuerpo de doctrina sobre el crédito, que ha tendido a mostrar que los bancos no son un «velo» (banks are not a veil) en la transmisión de los impulsos monetarios, y también a destacar lo especifico de los mercados crediticios. En cualquier caso, debe señalarse que se trata de teorias que no han alcanzado todavia un pleno desarrollo, y, en consecuencia, deben ser aplicadas con cierta precaución ?.

El punto de partida de la nueva teoría sobre los bancos pone todo el énfasis en señalar que los mercados crediticios no son como los demás mercados. Los créditos sólo se intercambian por promesas de pago en el futuro, y la calidad de estas promesas es diversa e incierta. De este modo, los costes de información serán especialmente relevantes, con la particularidad de que la información que circula en los mercados del crédito es imperfecta y asimétrica ${ }^{8}$. Que la información es "asimétrica» significa que quien pide el crédito conoce con mayor exactitud que la institución financiera cuál es la verdadera probabilidad de éxito del proyecto de inversión subyacente. Estos problemas de información condicionan las relaciones entre oferentes y demandantes de crédito, y además modifican la transmision de los efectos de la política monetaria.

A causa de estos condicionantes, los tipos de interés (el precio del crédito) pueden fallar en su función de asignar eficientemente los recursos financieros, $y$, precisamente por ello, altos tipos de interés no significarán siempre una mayor disponibilidad de crédito. Es entonces cuando aparece la posibilidad de que exista un equilibrio con «racionamiento del crédito».

La expresión «racionamiento del crédito», que traduce el término inglés credit rationing, puede provocar alguna confusión, pero es la que tiende a usarse en la literatura actual de teoría económica ${ }^{9}$. Siguiendo una conocida defini-

"Véase un resumen de los origenes de la moderna teoria del crédito en Jaffee (1987).

Baste decir que los autores monetaristas se han enfrentado decididamente con estas nuevas teorias que cuestionan la exogeneidad de la oferta monetaria y que tienden a encontrar fallos en los mercados crediticios. Véase, por ejemplo, Brunner y Meltzer (1988).

' El primer trabajo que desarrollo este punto de vista fue el de Jaffee y Russell (1976), cuyas fuentes de inspiración fueron autores institucionalistas como Arrow o Akerlof.

${ }^{9}$ El Diccionario de la Real Academia de la Lengua Española admite que «racionar» es adis. tribuir raciones o proveer de ellas a las tropasw, y también «someter a los articulos de primera necesidad en caso de escasez a una distribución establecida por la autoridadm. Pareceria asi que ninguna acepción cuadra bien con la traducción que utilizamos del termino ingles credit ratroning pero, sin embargo, es la que presentan prestigiosos diccionarios inglés-español como el de Williams Collins Sons and Co. Por otra parte, es éste un termino que se esta introduciendo rápida- 
ción, cabe señalar que un prestatario sufre racionamiento de crédito si no puede acceder a toda la cantidad que demanda aunque acepte el tipo de interés que se le exige, o si en relación con otros prestatarios idénticos no se le concede la cantidad de crédito que los demás si obtienen. También habrá racionamiento en el caso de un mismo prestatario que en una coyuntura normal obtiene crédito sin dificultad, y en una coyuntura de crisis, al haberse incrementado los costes de información y transacción, se le raciona su capacidad de endeudamiento ${ }^{10}$.

Pero ¿por qué las instituciones financieras preferirán en muchas ocasiones racionar el credito antes que elevar los tipos de interés? La principal explicación se encuentra en un influyente articulo de Stiglitz y Weiss, y consiste en que el tipo de interés que un banco carga sobre los créditos que concede puede afectar a la calidad del riesgo total que está dispuesto a asumir ". Asi, mayores tipos de interés pueden inducir problemas de «riesgo moral» (moral hazard), que incentiven a los prestatarios a comprometerse en proyectos de inversion mas arriesgados, y problemas de «selección adversa» (adverse selection), de tal modo que prestatarios con mayor aversión al riesgo dejen paso a otros mucho más aventurados ${ }^{12}$.

Uno de los mayores problemas que tiene todo este enfoque teórico es su dificultad de ser contrastado con la realidad. La demanda y la oferta de crédito no son directamente observables, y lo único que se conoce ex post es la cantidad de crédito efectivamente puesta a disposición de la economía. Sin embargo, desde un punto de vista macroeconómico, se ha apuntado la posibilidad de obtener algunos indicadores indirectos de la presencia del racionamiento crediticio. Concretamente, Jaffee propone cuatro técnicas: a) análisis estadistico de secciones transversales sobre la oferta del crédito bancario; $b$ ) análisis estadístico de series temporales sobre la oferta del crédito bancario; $c$ ) estudio de las encuestas de opinión sobre la coyuntura crediticia; $d$ ) estudio de un conjunto de indicadores (proxies) ${ }^{13}$. Lamentablemente, la mala calidad de las estadisticas españolas del período que estudiamos (1930-1935) nos impiden afrontar con confianza las técnicas $a$ ) y b). Por eso, aun reconociendo las limitaciones que encierran, nos hemos centrado en la búsqueda de documentación

mente en el analisis monetario español. Por eso he querido mantenerlo asi, y en el texto serán equivalentes «racionamiento del créditon y «restricción del créditom.

10 Vease Keeton (1979).

11 Stiglitz y Weiss (1981).

12 Es importante señalar que estas teorías defienden la existencia de racionamiento en situaciones de equilibrio, y, por tanto, son aplicables en todo momento y lugar. Véase Blinder (1987).

1) Jaffee (1971), capitulo 3. 
contemporanea que nos informe sobre cómo se vivió la coyuntura económica, y en la comprobación de tres de los indicadores que propone Jaffee:

1. Si hay racionamiento del crédito se producirá una recomposición de la cartera de inversiones de los bancos en favor de los activos sin riesgo (principalmente fondos públicos) it.

2. Si hay racionamiento del crédito se producirá un acortamiento del plazo de las operaciones crediticias, operándose un desplazamiento hacia el descuento comercial en detrimento de los préstamos.

3. Si hay racionamiento del crédito, éste debería tener una especial incidencia en el componente de inversión de la demanda agregada ${ }^{15}$.

Naturalmente, un examen muy detenido de los registros bancarios de peticiones aprobadas y denegadas de crédito podria dar alguna respuesta más apurada. Pero esto es raramente factible, y por eso los indicadores indirectos pueden sernos de cierta utilidad.

A los tres indicadores señalados podriamos añadir uno de los «multiplicadores del crédito» $(k)$ que se han propuesto ${ }^{16}$, y que resultaria de la relación:

$$
\mathrm{CR}=\mathrm{k} \cdot \mathrm{BM} \text {, }
$$

donde CR es el crédito bancario y BM la base monetaria. Si durante una crisis hay racionamiento del crédito el multiplicador $\mathrm{k}$ deberia evolucionar peor que el multiplicador monetario que relaciona la oferta monetaria con la base monetaria.

Finalmente, conviene destacar que la magnitud del racionamiento del crédito siempre dependerá de la capacidad del sistema financiero para reducir lo que Bernanke llama «Costes de Intermediación Crediticia» (CIC), expresión que resume los costes de información y transacción antes señalados ${ }^{17}$. En este

14 Jaffee (1971). En Jaffee y Modigliani (1969) se propone como proxy del racionamiento del crédito $\mathrm{H} /-\mathrm{Ll} / \mathrm{L}$, donde $\mathrm{Ll}$ son los créditos a empresas sin riesgo y $\mathrm{L}$ es el total de créditos concedidos. Luego se demuestra que estc indicador es una funcion monotona de la medida ideal, y tambien que los bancos tienden a discriminar en contra de las pequeñas y medianas empresas al considerar menos arriesgados los préstamos a grandes empresas.

is Blinder (1987) ha querido plantear, a partir de este punto, las bases para una teoria de la "oferta efectiva», que complemente la teoria de la «demanda efectiva" keynesiana sobre bases no clásicas.

\footnotetext{
16 Vease, de nuevo, Blinder (1987).

1) Vease Bernanke (1983).
} 
sentido, la disponibilidad de servicios de información, la profesionalidad de los criterios de decisión y el grado de perfeccionamiento de los contratos se revelan fundamentales. Por otro lado, también debe señalarse que una coyuntura económica adversa incrementa los $\mathrm{CIC}$, y este factor puede terminar por resuitar decisivo. Asi, para Bernanke, la crisis bancaria norteamericana de la década de 1930 tuvo mucho que ver con estos fenómenos, y ella fue la verdadera responsable de la extensión y gravedad que alcanzó la Gran Depresión.

\section{UNA CARACTERIZACION DEL SISTEMA FINANCIERO ESPAÑOL. EN 1930-1935}

En 1923 habia 106 bancos inscritos en la Comisaria Regia; en 1930 la cifra ascenderia hasta 127, para caer en los años posteriores hasta los 115 de 1935. Aunque la banca española habia crecido a un elevado ritmo desde la I Guerra Mundial, el atraso acumulado con anterioridad hacia que el Coeficiente de Intermediación Financiera (CIF) de Goldsmith (Activo Total de las Instituciones Financieras/Renta Nacional) estuviera en España durante la década de 1930 en torno a la mitad de la media de la Europa Occidental ${ }^{18}$.

Lo cierto es que si el sistema financiero español estaba lejos de los parámetros de su entorno, también lo estaba de los del actual Tercer Mundo, duplicando, por ejemplo, el CIF que se ha calculado para la India en esa década ${ }^{19}$. Todo ello se corresponde bastante bien con las conclusiones finales de Prados de la Escosura para la economia real, cuando sostiene que la España anterior a la Guerra Civil distaba mucho de las naciones desarrolladas de la Europa Occidental, pero que éstas siempre habian sido su «paradigma secular» 20.

Durante la Dictadura de Primo de Rivera, la banca privada habia conocido un gran desarrollo tras la crisis de 1920-1925, hasta el punto que se ha medido el avance del capitalismo en ese periodo por la expansión de los cinco mayores bancos ${ }^{21}$. Aun así, el crecimiento fue desigual, favoreciendo más a la banca del centro (Zona A) y a la banca de influencia catalana (Zona C) que a la banca del norte (Zona B). Sin embargo, este hecho se verá compensado porque desde 1926 la gran banca cambiará su especialización regional por la participación en actividades a escala nacional, abriendo numerosas sucursales fuera

\footnotetext{
Ir Martín Aceña (1985a), p. 139.

19 Goldsmith (1983).

20. Prados de la Escosura (1988).

2 Velarde (1973), p. 251.
} 
de su zona de origen ${ }^{22}$. El número total de oficinas pasará de 270 en 1919 a 931 en 1926 y 1.892 en $1936^{23}$, mientras las sucursales operativas de los cinco mayores bancos (Español de Crédito, Vizcaya, Central, Hispano Americano y Bilbao) crecerán de 160 en 1921 a 856 en $1931^{24}$. Asi, la gran banca nacional se articulará como centro y eje del sistema, «nacionalizandose» al imponer res. tricciones al desarrollo de la competencia de la banca extranjera ${ }^{25}$.

El proceso de expansión de la gran banca continuo durante la Segunda República, auxiliado por la absorción de pequeñas entidades con problemas, hasta el punto de que la Federación de la Banca Local se dirigió en 1933 al Consejo Superior Bancario para pedir medidas que limitaran la expansión de la gran banca ${ }^{26}$. Sin embargo, hay que senalar que en aquel momento la tendencia a la concentración gozaría de gran aceptación social, siendo bien vista, por ejemplo, por Indalecio Prieto (Revista de Economía y Hacienda, 1931, núm. 25), e incluso por el sindicato Union General de Trabajadores (Bancario, 1933, núm. 28), aunque este último temiera que «no entrasen en juego altos intereses, y si, únicamente, los de ciertos grupos bancarios». Sin embargo, el crecimiento de los depósitos será vacilante en 1930 y experimentará una aguda crisis en el segundo y tercer trimestre de 1931, para irse recuperando de forma lenta pero constante desde entonces. El proceso por zonas bancarias se. rá desigual, y la zona $\mathrm{C}$ irá perdiendo participación en los depósitos totales de forma continua mientras que la zona A perderá cuota en un primer momento para recuperarse desde 1933, y absorber a principios de 1936 más del 48 por 100 del total. La zona B verá crecer su participación hasta 1932, momento en el que inicia su declive. Al final, el indice de Herfindahl que hemos elaborado indica sólo un ligero incremento en la concentración como resultado final (véase cuadro 1 ).

En resumen, la banca privada española de la década de 1930, que junto al Banco de España representaba en torno al 80 por 100 del total de activos del sistema financiero ${ }^{27}$, parecía ser un sector relativamente pequeño, aislado de

22 Belford (1979).

23 Alvarez. Llano y Andreu (1982), p. 130.

24 Consejo Superior Bancario (1954).

${ }^{25}$ Muñoz (1978), pp. 159.162.

2t Véase El Sol, t de noviembre de 1933. Sin embargo, hay que senalar que en aquel momento la tendencia a la concentración gozaria de gran aceptación social, siendo bien vista, por ejemplo, por Indalecio Prieto (Revista de Economia y Hacienda, 1931, num. 25), e incluso por el sindicato Unión General de Trabajadores (Bancario, 1933, num. 28), aunque este último temicra que «no entrasen en juego altos intereses, $y$ si, únicamente, los de ciertos grupos bancarios».

2i Cifra estimada sobre datos de Martin Aceña (1985a, p. 129). 
la competencia exterior, y con altos costes operativos derivados de una apresurada expansión geográfica.

\section{CUADRO 1}

Evolución de los depósitos por zonas bancarias de la banca inscrita (millones de pesetas corrientes), 1929-1935

\begin{tabular}{|c|c|c|c|c|c|}
\hline & $\begin{array}{c}\text { Depósitos } \\
\text { totales }\end{array}$ & OLOna $A$ & $v_{i Z \text { Zona } B}$ & rizonaC. & $I . H$ \\
\hline 1929.4 & $6.08+.1$ & 47,52 & 35.44 & 17.04 & 0,380 \\
\hline $1930.1 \ldots \ldots \ldots \ldots$ & $6.557,7$ & 48,57 & 35,14 & $16,2^{9}$ & 0,386 \\
\hline $1930.2 \ldots \ldots \ldots$ & $6.874,9$ & +9.10 & 34,64 & 16,26 & 0.388 \\
\hline 1930.3 & $6.731,2$ & 47.38 & 35,92 & 16,70 & 0,381 \\
\hline $1930.4 \ldots \ldots$ & $6.568,0$ & 46,21 & 36,78 & 17,01 & 0,378 \\
\hline $1931.1 \ldots \ldots \ldots \ldots \ldots \ldots$ & $6.736,0$ & 46,98 & 36,02 & 17,00 & 0,379 \\
\hline $1931.2 \ldots \ldots \ldots \ldots \ldots \ldots$ & $5.762,2$ & 44,78 & 39,18 & 16,04 & 0,380 \\
\hline $1931.3 \ldots \ldots \ldots \ldots \ldots \ldots$ & 5.344 .2 & 43.64 & 40,79 & 15.57 & 0,381 \\
\hline $1931.4 \ldots$ & $5.375,6$ & 43.75 & 41,08 & 15,17 & 0,383 \\
\hline 1932.1 & $5.599,5$ & $+4,53$ & 40,24 & 15,23 & 0.383 \\
\hline 1932.2 & 5.736 .4 & 44,85 & 40,20 & 14,95 & 0.385 \\
\hline 1932.3 & $5.754,8$ & 44,70 & 40,60 & 14,70 & 0,386 \\
\hline 1932.4 & $5.812,4$ & 45.23 & 40,33 & 14,44 & 0,388 \\
\hline 1933.1 & 5.979 .1 & 44,91 & 39,93 & 15,16 & 0,384 \\
\hline 1933.2 & $6.060,1$ & 44,99 & 39,85 & 15,16 & 0,384 \\
\hline 1933.3 & 6.056 .7 & 45.37 & 39.76 & 14,87 & 0,386 \\
\hline 1933.4 & $6.077,0$ & 45,34 & 39,65 & 15,01 & 0,385 \\
\hline$\ldots \ldots+\cdots, \cdots, \cdots$, & $6.302,1$ & 46,67 & 38,87 & 14,46 & 0,390 \\
\hline 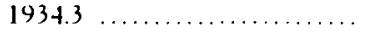 & $6,363,3$ & 46,43 & 38,92 & 14,65 & 0,389 \\
\hline 1934.4 & 6.556 .4 & 47.56 & 37.44 & 15,00 & 0,389 \\
\hline 1935.1 & 6.679 .4 & 47.95 & $3 \bar{i}, 41$ & 14.64 & 0,391 \\
\hline 1935.2 & 6.772 .8 & 48,18 & 37.20 & 14,62 & 0,392 \\
\hline 1935.3 & 6.887 .3 & 48,79 & 37,34 & 13,87 & 0,397 \\
\hline$\ldots \ldots+\ldots, \ldots, \ldots$, & 7.128 .1 & 48,81 & 37,16 & 14.03 & 0,396 \\
\hline
\end{tabular}

Nota: IH es el indice de Herfindahl, que mide la concentración con menos sesgos que otros indicadores. En este caso. IH $\mathrm{H}=\Sigma(\mathrm{Di} / \mathrm{D})^{2}$, donde $\mathrm{Di}$ es la participación de la zona $i$ en los depósitos totales que representa $D$. La maxima concentración es 1 y la minima $1 / \mathrm{n}$, es decir, 0.333 en nuestro caso.

Fitente: Boletines del Consejo Superior Bancario y Martin Aceña (1985b).

Por otro lado, las cajas de ahorro funcionaban como entidades de ahorro popular, sin fines de lucro, y gozando de protección oficial. Sus operaciones activas eran muy limitadas, estando orientadas hacia los Fondos Públicos y pe- 
queños préstamos con la garantia de valores püblicos, ropas y, principalmente, alhajas. Así, se ha estimado que los préstamos representaban menos de una cuarta parte de los depósitos ${ }^{28}$. En cuanto a su organización, cabe decir que mejoró durante la Segunda República con la creación en 1933 del Instituto de Crédito de las Cajas Generales de Ahorro Popular (ICCA), pero el poco conocido intento de extender sus actividades al crédito hipotecario fracasó. En efecto, el articulo 22 del nuevo Estatuto aprobado el 14 de marzo de 1933 abria la posibilidad de que las cajas participasen en las «cesiones o traspasos de créditos hipotecarios». Las cajas intentaron introducirse en este mercado con la emisión de cedulas hipotecarias por el ICCA, pero la frontal oposición del Banco Hipotecario, alegando la «evidente imposibilidad» de esta operatoria al mantenerse el privilegio de 1875, reiterado por Real Decreto del 3 de noviembre de 1928 (ley del 9 de septiembre de 1931), fue decisiva ${ }^{29}$.

Finalmente, existia un pequeño núcleo de banca oficial, formado por el Banco Hipotecario (fundado en 1872), el Banco de Crédito Industrial (fundado en 1919), el Banco de Crédito Local (fundado en 1925) y el Banco Exterior de España (fundado en 1929). A ellos cabría añadir la Caja Central del Crédito Maritimo y Pesquero (desde 1919) y el Servicio Nacional de Crédito Agricola (desde 1925), aunque ambas entidades funcionaban más bien como servicios administrativos. La importancia de la banca oficial en la actividad crediticia era muy limitada. Además, sus cotas máximas las alcanzaron en 1931, cuando el Banco de Crédito Industrial alcanzó un volumen de préstamos que era el 7,2 por 100 del total concedido por la banca privada, y el Banco Hipotecario de Espana elevó su montante en relación con esa cifra hasta el 9,5 por 100 30.

Resulta oportuno señalar que en un pais todavía predominantemente agrario el crédito al campo seguía gravemente desatendido. Las insuficiencias del Servicio Nacional de Crédito Agricola, junto con las expectativas levantadas por la reforma agraria propuesta, hicieron que se levantasen numerosas voces y se overan las más diversas argumentaciones sobre este tema. En el verano

28 Forniés (1983), p. 84 .

${ }^{29}$ Véase A.H.B.E. Caja 153. Este fue el principal enfrentamiento de las cajas con el resto del sistema financiero. Por ello. creo que Fornies (1983) exagera cuando habla de «intentos llevados a cabo por la banca privada para suprimir a las cajas de ahorros», en oposición al «entendimiento Gobierno-Cajas». Por el contrario, bancos y cajas mantuvicron frecuentes contactos para repartirse el mercado del ahorro, estableciendo acuerdos de precios y unificación de productos. Véase, por ejemplo, A.H.B.E. Caja 153. Acta de la Junta Consultiva de las Cajas Generales de Ahorro Popular de fecha 5 de abril de 1933

") Datos del Banco de Crédito Industrial en Tortella y Jimenez (1986), p. 238, y del Banco Hipotecario de España en Lacomba y Ruiz (1990), pp. 337.339. 
de 1933, cuando se abrió formalmente el debate sobre la creación de un Banco Nacional Agrario, el Consejo Superior Bancario se uniria al Banco Hipotecario y al mismo Banco de España para frenar su creación ${ }^{31}$. Cabe también indicar que para dar respuesta a algunas líneas de financiación insuficientemente atendidas (principalmente crédito agrario y crédito hipotecario) fueron apareciendo sociedades cooperativas, que, sin embargo, siempre encontraron la enconada resistencia del Consejo Superior Bancario que no permitio su inscripción en el Registro Oficial ${ }^{32}$.

Por todo ello, parece que sólo la actividad crediticia de la banca privada mantendrá una relación estrecha con la inversión directamente productiva, $y$, asi, limitaremos nuestro análisis tan sólo a examinar su comportamiento durante la coyuntura de 1930-1935. Empezaremos concentrando nuestra atención en realizar una aproximación al proceso de modernización de los mecanismos operativos de la actividad bancaria. Con ello pretendemos obtener una primera medida de los Costes de Intermediación Crediticia (CIC), tan importantes en el marco del análisis propuesto.

En un trabajo pionero en esta linea se estudia el proceso de difusión de algunas innovaciones en el caso histórico de las empresas bancarias españolas, señalándose que las instituciones financieras contaron por primera vez con un organigrama funcional en 1872, un organigrama divisional en 1903, un Departamento Internacional en 1925 y un Servicio de Estudios y un sistema organizado de planificación en 1934, aunque su difusión posterior sería considerablemente lenta ${ }^{33}$.

Pero un hecho particularmente significativo del atraso operativo de la banca española lo constituye la tardía implantación de las cámaras de compensación bancaria. En España habria que esperar al Real Decreto del 30 de marzo de 1905 para contar con una primera disposición que otorgara al Gobierno la facultad de crear cámaras de liquidación del movimiento diario de cartera. Aunque el alcance de esta compensación era limitado, pues no incluia los che. ques, nunca seria desarrollada, y sólo por Real Decreto del 9 de enero de 1923 el recién creado Consejo Superior Bancario sentaria las bases de la moderna compensación en España ${ }^{34}$. Las primeras cámaras de compensación serian las

3 Véase Esparia Bancaria, 1933, nums. 5, 20 y 22. Tambièn, A.H.B.E. Dirección General de Sucursales, Leg. 2248, donde se contiene el Informe que se pidio al Banco de España.

32 Vease A.H.B.E. Cajas 58.61.

33 Para que la difusión alcanzase al 50 por 100 de la muestra, se necesitaron 44 años en el caso del organigrama funcional, 67 años en el caso del organigrama divisional, 41 años en cuanto al sistema organizado de planificacion, 29 años en cuanto al Departamento Internacional y 36 años en cuanto al Servicio de Estudios. Véase Polo (1988), p. 181.

is Segun el documentado estudio de Cagigal (1922), las fechas de fundación de otras camaras 
de Madrid, Barcelona y Bilbao ${ }^{35}$. Con todo, habrian de pasar siete años hasta que el Banco de España se incorporase a este mecanismo, hecho que, como se señala en un Informe del Consejo Superior Bancario, publicado en 1930, limitó en gran parte la operatividad de las cámaras dado el peso del banco emisor en la estructura financiera española. Finalmente, el Banco de España accederia a estar presente en las cámaras satisfaciendo la cuota de entrada que era de 2.000 pesetas y la cuota anual de 1.750 pesetas ${ }^{36}$. Por otra parte, el citado Informe pediria nuevas cámaras para Sevilla, Córdoba, Granada, Valencia, San Sebastián, Pamplona, Oviedo, Gijón, La Coruña, Valladolid, Cáceres y Toledo, que deberian organizarse con arreglo al tipo más económico, sencillo y rápido, que, en su opinión, no era otro que el de las cámaras de compensación de Suecia.

El Banco de España también manifestaba un atraso notorio en la instrumentación de la política monetaria, al carecer de un mecanismo de open markert ya implantado en muchos paises. Todavia en 1935 se rechazaria la idea de introducirlo en España, argumentando la falta de costumbre del público y la carencia de una organización adecuada del mercado, y citando que éste era también el caso de Francia y Bélgica ${ }^{37}$. De esta forma quedaría explicada la rigidez de la política de tipos de interés que, por otra parte, era el instrumento principal de la politica monetaria española.

De este modo empezamos a tener razones para pensar que los costes de transacción en el sistema financiero español de la época debian ser muy elevados. Por otro lado, tampoco se disponia de mecanismos que redujeran los costes de información. Perpiña Grau, en 1934, propondría la creación de una Central de Clasificación de Créditos, a establecer en cada zona bancaria, y cuya existencia no deberia ser pública uporque con ello no se obtendria beneficio alguno y por el contrario acarrearia muchos peligros». La propuesta, que podemos considerar el primer antecedente de la moderna Central de Información de Riesgos (CIR) que funciona hoy en el seno del Banco de España, no fue llevada a la práctica. La misma suerte correría la propuesta que José Estra-

\footnotetext{
de compensación en el mundo habrian sido: Edimburgo, 1760; Londres, 1775; Dublin, 1846; Nueva York, 1853; Viena, 1864; Melhourne, 1868; Paris, 1872; Osaka, 1879; Italia, 1881; Berlin, 1883; Escandinavia, 1885; Halifax, 1887; Budapest, 1888; Buenos Aires, 1893; Praga, 1895; San Petersburgo, 1898; Bruselas, 1908; La Habana, 1921.

35 Véase España Económica y Financiera, 28 de julio de 1928, pp. 674-676.

36 Consejo Superior Bancario (1930), pp. 8 y ss. También, A.C.G.B.E., 4 de abril de 1930 y 14 de noviembre de 1930.

"BESE D. 6449. En Francia, tras la nacionalización de facto del Banco de Francia, por la ley del 24 de julio de 1936, entraria en funcionamiento el open market desde junio de 1938. Vease Bouvier (1984), pp. 67 y ss.
} 
gués lanzaria, al año siguiente, apoyando la creación de unas «sociedades fiduciarias», similares a las que ya operaban en Alemania y otros paises, para acometer la vigilancia del crédito. De hecho, hasta la aprobación de la Orden Ministerial del 13 de febrero de 1963 no se contemplaria la organización de la citada CIR ${ }^{38}$.

También cabe señalar que el marco legal bancario tenia lagunas importantes. Aunque la Ley de Ordenación Bancaria de 1931 introdujo un mayor grado de control sobre el sistema financiero (especialmente sobre el Banco de España), anticipando la corriente intervencionista que se extendería por todo el mundo poco después ${ }^{34}$, lo cierto es que seguirian existiendo instituciones muy particulares sin una regulación especifica. Un buen ejemplo de ello podría ser la famosa "cuenta de valores», de gran tradición en Cataluna. Sobre ella ya se habia pronunciado un Informe del Comité Interventor del Mercado Bursátil de Barcelona, publicado en 1928, cuando señaló que debería entendérsela como un préstamo ya que permitía recibir valores en propiedad, estimando la ponencia que no debían tolerarse «términos anfibológicos» que sólo podian conducir a la confusión y al error. Más tarde, en 1933, Gay de Montellá confirmaria que la «cuenta de valores» originaba una relación crediticia entre cliente (acreedor) y banco (deudor), y era preciso que como contrato se le dotase de normas legales. Sin embargo, hasta noviembre de 1935 el Consejo Superior Bancario no publicaría una normativa que regulase la "cuenta de valores» como contrato por el que un banco recibe y hace suyos titulos mobiliarios que le entrega una persona individual o jurídica, quedando obligado a devolver, en una o varias veces, una cantidad igual a la recibida y en títulos de la misma especie y calidad to.

Todo ello conduce a la conclusión de que los Costes de Intermediación Crediticia (CIC) en el sistema financiero español debian ser muy altos. De este modo, no debe sorprendernos que los criterios aplicados en el estudio de las operaciones crediticias fueran siempre muy conservadores. Prueba de ello es

38 Véanse las propuestas de Perpiña Grau y Estragues en Fspaña Bancaria, 1934, num. 39, y en España Bancaria, 1935, núm. 46, respectivamente. El unico mecanismo de información disponible era el Registro de Aceptaciones Impagadas (RAI), que fue creado en 1922 por la Asociación Española de la Banca del Centro de España (AEBCE), y que proporcionaba a sus asociados informacion sobre efectos comerciales devueltos impagados. Veanse las Memorias de la AEBC.E. depositadas en la biblioteca del Consejo Superior Bancario.

34 Vease Cassese (1984), quien relaciona el creciente intervencionismo bancario con los sucesivos abandonos del Patrón Oro ocurridos simultaneamente.

to Véasc Informe del Comite Interventor del Mercado Bursatil de Barcelona (1928), p. 108, y España Bancaria, 1933, núm. 20. 
que en un manual muy difundido en la época se enunciaran asi los principios ideales del creditman (sic):

1. Conocer los propios defectos es empezar a ser fuerte.

2. Todo el mundo es honrado hasta el momento en que deja de serlo.

3. Dos firmas valen más que una sola.

4. Tanto vale el negocio como el hombre que lo dirige.

A todo ello, según el autor, debería añadirse un «axioma clave»: la situación de una casa no se conoce realmente hasta después de liquidada '. Si pensamos que su autor, Georges Llobera, era un conocido profesor mercantil y apoderado de banca, que dirigia la revista $B a n c a$, autodefinida como el órgano cientifico de los profesionales de la banca, no cabe duda de que principios tan cautelosos debian gozar de gran aceptación entre los directivos de las oficinas bancarias.

\section{IV. ¿HUBO RACIONAMIENTO DE CRÉDITO EN LA ESPAÑA REPUBLICANA?}

La euforia producida por el crecimiento industrial durante la Dictadura de Primo de Rivera tendia a ocultar los puntos débiles de la estrategia de desarrollo que se siguió. Sin embargo, el Informe Anual sobre España del Departamento de Comercio Exterior británico correspondiente a 1929 veia con seria preocupación las propuestas para limitar las importaciones (principalmente de maquinaria y material de obras públicas), las teorias nacionalistas del gobierno que trataban de excluir al capital extranjero de los ferrocarriles, el refino y la distribución de petróleo, la minería y la ingeniería de aguas, asi como el intervencionismo que apoyaba tentativas y movimientos hacia la nacionalización de la banca y los seguros. En resumen, la prosperidad vigente era considerada «efimera»e inducida por un importante déficit público ${ }^{42}$.

En cualquier caso, con el fin de la República la paralización de las obras públicas en 1930 provocaria una crisis industrial que no terminaria de superarse en los cinco años siguientes. A ello se uniria la crisis del sector exterior, cayendo importaciones y exportaciones entre un 25 y un 50 por 100 , según las distintas estimaciones disponibles. Esta cifra es importante si tenemos en cuen-

\footnotetext{
4 Llobera (1932), p. 201

12 Vease Department of Overseas Trade (1930).
} 
ta que el grado de apertura de la economia española en 1929 era del 20,4 por $100^{43}$.

\section{CUADRO 2}

Evolución macroeconómica del sector real de la economia española en numeros indice. $1929=100$

\begin{tabular}{|c|c|c|c|c|c|c|}
\hline & Renta & $G N$ & Precios & $\begin{array}{c}\text { Intersion } \\
\text { total }\end{array}$ & $\begin{array}{l}\text { Inversion } \\
\text { privada }\end{array}$ & $\begin{array}{c}\text { Inverstón } \\
\text { piblica }\end{array}$ \\
\hline 1929 & 100,0 & 100,0 & 100,0 & 100,0 & 100,0 & 100,0 \\
\hline 1930 & 98,9 & 104,6 & 99,6 & 95,3 & 98,4 & 45.0 \\
\hline 1931 & 100,2 & 92,7 & 100,6 & 73,5 & 70,8 & 52,5 \\
\hline 1932 & 103.4 & 104,0 & 99,3 & 61,4 & 56,0 & 67,5 \\
\hline 1933 & 101,5 & 97,7 & 94.8 & 57,5 & 46,0 & 97.5 \\
\hline 1934 & 109,6 & 102,0 & 97,4 & 62,4 & 49,7 & 102,5 \\
\hline 1935 & 107.9 & 95.6 & 97,9 & 67.2 & 58,2 & 80,0 \\
\hline
\end{tabular}

FLextes: Renta = Renta nominal, tomada de Alcaide (1976). ( $\mathrm{N}$ = Ciasto nacional, tomado de Carreras (1985). Precios = Indice de precios al por mayor, tomado del Ministerio de Trabajo (1942). Inversion CEN, tomada de París Eguilaz (1965). Inversion privada, tomada de Carreras (1985). Inversión pública, tomada de Carreras (1985).

Sin embargo, el distinto impacto sectorial, el mantenimiento de los niveles de renta (ayudado por las buenas cosechas de 1932 y 1934) y la sólo ligera caída de los precios en estos años han dado argumentos para sostener una interesante polémica sobre el alcance real de la crisis y su conexión con el fenómeno internacional de la Gran Depresión ${ }^{+4}$. Recientemente, Comin ha señalado que hay acuerdo en que la crisis industrial española de la década de 1930 fue menos grave que en otros paises europeos, pero ello no parece motivo suficiente para tildar a España de diferente, como sugiere Palafox ${ }^{45}$. En cualquier caso, uno de los aspectos más olvidados en toda esta discusión es el comportamien. to de la inversión. Como muestra el cuadro 2, tanto las estimaciones del Consejo de Economía Nacional (CEN) como las más recientes realizadas por $\mathrm{Al}$ -

\footnotetext{
"Tena (1989), p. 331.

4t Vease Hernandez Andreu (1980 y 1986) y Palafox (1980).

4 Comin (1987). Una versión actualizada de la tesis del profesor Jordi Palafox se encuentra en Palafox (1991).
} 


\section{CUADRO 3}

Evolución de las magnitudes monetarias de la economía española en números indices. $1929=100$

\begin{tabular}{lllllll}
\hline & Oimon & Basmon & Crédno & Credpriv & Halimon & Mulibun \\
\hline $1929 \ldots \ldots \ldots \ldots \ldots$ & 100,0 & 100,0 & 100,0 & 100,0 & 100,0 & 100,0 \\
$1930 \ldots \ldots \ldots \ldots \ldots \ldots$ & 106,4 & 102,8 & 102,6 & 104,1 & 103,2 & 100,0 \\
$1931 \ldots \ldots \ldots \ldots \ldots \ldots$ & 103,7 & 113,6 & 105,0 & 82,5 & 90,8 & 93,2 \\
$1932 \ldots \ldots \ldots \ldots \ldots \ldots$ & 104,6 & 108,7 & 102,2 & 85,3 & 96,2 & 94,2 \\
$1933 \ldots \ldots \ldots \ldots \ldots$ & 106,9 & 108,0 & 103,6 & 90,6 & 98,9 & 96,1 \\
$1934 \ldots \ldots \ldots \ldots \ldots$ & 110,2 & 104,3 & 101,1 & 90,6 & 105,3 & 97,1 \\
$1935 \ldots \ldots \ldots \ldots \ldots$ & 114,4 & 110,2 & 93,5 & 87,0 & 103,7 & 85,5 \\
\hline
\end{tabular}

Notas: Ofmon $=$ Oferta monetaria (M3). Basmon $=$ Base monetaria. Credito $=$ Total credito (Banca privada + Banco de Españal Credpriv $=$ Crédito de la Banca Privada. Multmon $=$ Multiplicador monetario (Ofmon Basmon). Multban = Multiplicador del credito (Credito Basmon).

Frixtr: Martin Accìa 41985 bl.

\section{CUADRO 4}

Evolución de la tasa de descuento de los bancos centrales en términos reales, 1930-1935

\begin{tabular}{|c|c|c|c|c|c|c|}
\hline & 1930 & 1931 & 1932 & 1933 & 1934 & 1935 \\
\hline Alemania & 13,93 & 17,84 & 18.79 & 6,85 & $-1,88$ & 0,72 \\
\hline Austria ........................ & 14,75 & 14,73 & 4,44 & 8,73 & 2,34 & 4,25 \\
\hline Checoslovaquia $\ldots \ldots \ldots \ldots \ldots$ & 15,44 & 13,78 & 13,79 & 6,27 & 0,72 & 0,55 \\
\hline Francia .......... & 15,71 & 17,05 & 14.66 & 7,11 & 7,49 & 5,08 \\
\hline Italia .... & 15,93 & 19,21 & 11,97 & 13,43 & 4,61 & $-5,73$ \\
\hline Paises Bajos ................. & 15,21 & 17,25 & 15,98 & 5,94 & 2,50 & 3,17 \\
\hline 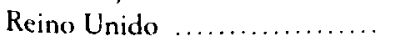 & 15,42 & 16,43 & 5,60 & 2,00 & $-2,00$ & 2,00 \\
\hline Suecia ... & 16,72 & 13,28 & 5,65 & 5,73 & $-4,07$ & $-3,67$ \\
\hline Suiza & 13,89 & 14,38 & 14,82 & 6,41 & 3,53 & 2,50 \\
\hline$\ldots \ldots \ldots \ldots \ldots \ldots$ & 5,73 & 5,24 & 8,39 & 10,04 & 3,80 & 4,46 \\
\hline
\end{tabular}

FIENTE: Tasa de descuento nominal en SDN (1937), p. 242. Indice de precios al por mayor en Mitchell (1975), pp. 738.739 . 
bert Carreras muestran una caida muy importante en esta magnitud, de tal modo que en 1933 el nivel de inversión era aproximadamente la mitad que en 1929, siguiendo una lenta recuperación en 1934 y 1935 . Esta es, sin embargo, la variable del sector real sobre la que más inciden los factores del modelo de racionamiento crediticio propuesto en la Sección II th.

En este sentido, el cuadro 3 ofrece un resumen de la evolución de las principales magnitudes monetarias. Resulta evidente que frente al crecimiento, aunque moderado, de la base monetaria y de la oferta monetaria, el crédito al sector privado quedará rezagado, de tal modo que el multiplicador del crédito estará permanentemente por debajo de su nivel en 1929 mientras que el multiplicador monetario conseguirá recuperarse. De este modo tendremos un primer indicio de racionamiento en la oferta de crédito.

\section{CUADRO 5}

Tipos de interés de las obligaciones del Estado a Largo plazo, 1929-1935

\begin{tabular}{lcccccc}
\hline & Francia & Holanda & España & R. Unido & EE.UL! \\
\hline $1929 \ldots \ldots \ldots \ldots \ldots \ldots \ldots \ldots \ldots \ldots$ & 3,98 & 3,97 & 5,39 & 4,60 & 3,60 \\
$1932 \ldots \ldots \ldots \ldots \ldots \ldots \ldots \ldots \ldots \ldots$ & 3,84 & 3,89 & 6,29 & 3,76 & 3,68 \\
$1933 \ldots \ldots \ldots \ldots \ldots \ldots \ldots \ldots \ldots$ & 4,38 & 3,68 & 6,04 & 3,38 & 3,31 \\
$1935 \ldots \ldots \ldots \ldots \ldots \ldots \ldots \ldots \ldots$ & 3,88 & 3,35 & 5,21 & 2,89 & 2,79 \\
\hline
\end{tabular}

Funte: United Nations (1952), p. 436.

Cabe advertir que plantear hipótesis sobre la existencia de racionamiento del crédito en este periodo es procedente, pues los tipos de interés se mantuvieron muy elevados en España, tanto en términos nominales como reales. Esto se confirma en los cuadros 4 y 5 , que nos ofrecen la evolución de los tipos de interés a corto plazo (en términos reales) y a largo plazo (en términos nominales). El cuadro 4 es la prolongación hasta 1935 del que se muestra en un trabajo de Martin Aceña para 1930 y 1931, y contradice desde 1932 su afirmación de que los tipos de interés reales en España estuvieron entre los más bajos del mundo ${ }^{+7}$. La razón fundamental estriba en que desde 1932 se exten-

to Desde una perspectiva mas convencional, en Aldcroft $(1970)$ ya se reconoce que en la Gran Bretaña de la decada de 1930 la disponibilidad de los bancos a prestar ejercio una influencia sobre las decisiones de inversión superior a la del tipo de interes.

4: Martin Aceña (1984), p. 259. 


\section{CUADRO 6}

Bajas en el Registro de Bancos y banqueros 1930-1936

\begin{tabular}{|c|c|c|c|c|c|}
\hline & Sede & Clase & F. Insc. & F. Baja & Causo \\
\hline \multicolumn{6}{|l|}{ ZONA A } \\
\hline \multicolumn{6}{|l|}{ 1. Banco Cooperativo del Comcrcio } \\
\hline$y$ de la Industria . & Madrid & B & 17.08 .22 & 21.07 .31 & $\mathrm{D}$ \\
\hline 2. Gregorio Cano y Cia. ............. & Madrid & $\mathrm{b}$ & 17.08 .22 & 23.06 .22 & $\mathrm{D}$ \\
\hline 3. Gonzalez del Valle y Cía. & Madrid & b & 17.08 .22 & 12.34 & $S$ \\
\hline 4. Bauer y Cia..... & Madrid & $b$ & 17.08 .22 & 05.07 .31 & $S$ \\
\hline 5. Corrales Hermanos. & Madrid & b & 17.08 .22 & 07.33 & C \\
\hline 6. Banco Manchego ................... & Valdepeñas & B & 14.10 .22 & 31 & $\mathrm{D}$ \\
\hline 7. Lazard Brothers & Madrid & B & 14.10 .22 & - & $\mathrm{D}$ \\
\hline 8. Banco Calamarte & Madrid & B & 27.09 .23 & 31 & $\mathrm{D}$ \\
\hline 9. Smith, Horn y Cia. S en C. ....... & Madrid & b & 26.10 .27 & - & C: \\
\hline 10. Jose Diaz Casero . ................. & Manzanares & b & 21.11 .28 & 33 & $\mathrm{D}$ \\
\hline 11. Valeriano Pérez Jiménez ........... & Rute & $\mathrm{b}$ & 11.07 .28 & 32 & $\mathrm{D}$ \\
\hline 12. Francisco Reina Framis ........... & P. Genil & $\mathbf{b}$ & 22.01 .30 & 31.12 .34 & $\mathrm{D}$ \\
\hline 13. José Benaytez Quesada .... & Almagro & $b$ & 19.02 .30 & - & $\mathrm{T}$ \\
\hline 14. Adolfo Garcia Calamarte .......... & Madrid & b & 21.01 .31 & - & C \\
\hline \multicolumn{6}{|l|}{ ZONA B } \\
\hline 1. Banco Gijonés de Crédito ......... & Gijón & B & 17.08 .22 & 11.32 & $\mathrm{~T}$ \\
\hline 2. Banco de Burgos .................. & Burgos & B & 17.08 .22 & 30 & D) \\
\hline 3. Idez. Mendirichaga y Cia......... & Bilbao & $b$ & 17.08 .22 & 36 & $\mathrm{D}$ \\
\hline t. Smith Horn y Cía. ................. & Bilbao & b & 17.08 .22 & 31 & $\mathrm{D}$ \\
\hline 5. Manuel Castellón y Cia ............ & Bilbao & $b$ & 17.08 .22 & 30 & D \\
\hline 6. Vda. e Ilijos de Carlos de Casas ... & Ribadeo & $b$ & 17.08 .22 & 34 & $S$ \\
\hline 7. Manuel Castellón y Mac-Mahón .. & Bilbao & $b$ & 02.12 .30 & 31 & $\mathrm{D}$ \\
\hline \multicolumn{6}{|l|}{ ZONA C } \\
\hline 1. J. Antonio Gómez Quiles & Cartagena & $b$ & 17.08 .22 & 30 & $\mathrm{D}$ \\
\hline 2. Banco de Préstamos y Descuentos & Barcelona & $\mathrm{B}$ & 17.08 .22 & 30 & $\mathrm{D}$ \\
\hline 3. Banco de Cataluña ............... & Barcelona & $\mathrm{B}$ & 17.08 .22 & 07.07 .31 & $S$ \\
\hline 4. Banco de Granollers ................ & Granollers & B & 17.08 .22 & 15.01 .35 & $\mathrm{r}$ \\
\hline \multicolumn{6}{|l|}{ 5. Banco de Reus de Descuentos y } \\
\hline Préstamos $\ldots \ldots \ldots \ldots \ldots$ & Reus & B & 17.08 .22 & 15.01 .35 & $\mathrm{~T}$ \\
\hline 6. Banco de Palafrugell & Palafrugell & B & 17.08 .22 & 36 & $\mathrm{~S}$ \\
\hline 7. Vda de Antonio Vicens ........... & Alcoy & b & 14.10 .22 & 01.07 .36 & $\mathrm{D}$ \\
\hline 8. Banco Garriga Nogués ............ & Barcelona & B & 14.07 .26 & 21.06 .32 & $\mathrm{D}$ \\
\hline 9. Banca Llorens ............. & Lérida & $b$ & 15.05 .28 & - & $\mathrm{I}$ \\
\hline 10. Banco de Valores y Credito & Barcelona & B & 11.07 .28 & 10.32 & $\mathrm{~S}$ \\
\hline
\end{tabular}

Nota: $B=$ banco, $b=$ banquero, $D=$ disolución, cese de negocio, o liquidación, $S=$ suspension de pagos, $C=$ cambio de denominación o adscripción, $T=$ Traspaso.

Finte: AliBE, Caja 63. 
dieron las politicas de «dinero barato" (cheap money) por muchos paises, y al mantenerse España al margen de esta corriente llegaria a tener en 1935 los tipos reales más altos de la muestra seleccionada, con la única excepción de Francia, donde se practicaba una política monetaria muy ortodoxa. Los tipos nominales a largo plazo fueron asimismo sensiblemente superiores a los de muchos otros paises ${ }^{48}$.

Aun asi, en el trabajo de Martín Aceña se demuestra palmariamente que el Banco de España supo actuar durante la crisis de liquidez de 1931 con gran brillantez como prestamista de último recurso ${ }^{49}$. Resultado de ello seria un bajo número de quiebras y suspensiones de pagos en la banca, aunque, según los datos que muestra el cuadro 6 (procedentes del Registro de Bancos y Banqueros), junto a los bancos un número considerable de banqueros cerraron sus puertas, por uno u otro motivo, entre 1930 y julio de $1936^{\circ}$.

Pero sigamos las sugerencias de Jaffee, y tratemos de acercarnos a las opiniones de prestamistas y prestatarios sobre la coyuntura crediticia para descubrir si hay más indicios de la presencia del racionamiento en la concesión de créditos. En este sentido, todo parece indicar que la banca aprecio la coyuntura económica de 1931 -julio de 1936 como critica. Las Memorias de una muestra de cuatro grandes entidades, representantes de las distintas zonas bancarias, y que incluye al Banco Español de Credito (BANESTO), Banco Urquijo (BUR), Banco de Bilbao (BB) y Banco de Sabadell (BSAB) son coincidentes. Tras el optimismo de 1930, considerado como de "progresión ascendente» (BANESTO), «resultados normales y satisfactorios» (BSAB), y «más favorable aún que el de 1929» (BUR), la visión cambiará drásticamente en 1931. BA. NESTO se lamentará de ala paralización de los mercados nacionales de valores»; BUR, de «la contracción de actividades en todas las esferas»; BB, de «la depresion que ha sido general en todos los sectores», y BSAB no tiene inconveniente en reconocer que «la depresión bancaria de carácter general llevó a la restricción de créditos y a un mayor afianzamiento de las obligaciones».

En 1932 BANESTO alude al «marasmo sufrido por los negocios»; BB señala cómo se dejaron sentir «los efectos de la crisis mundial»; BUR se enorgullece de haber contribuido a remediar las dificultades de la industria, pero «sin

tK Homer y Sylla (1991), p. 540, llegan a decir que los tiposs de descuento en España durante la década de 1930 estuvieron entre los más altos del mundo.

4* Martín Aceña (1984), capitulo 6.

"Con todo, las cifras de la crisis bancaria española son moderadas; sobre todo si pensamos que en Estados Unidos la crisis cerró las puertas del 35 por 100 de los bancos, en Francia afectó a 276 entidades y en Italia a más de la mitad de los bancos. Véase el número especial dedicado a este tema en Journal of Eturopean Economic History: 1984, vol 13, num. 2. 
que ello quebrantase, de lo que estamos muy ciertos, los intereses que nos están confiados»; BSAB se expresa de modo parecido, recordando que se habia actuado «dentro de las normas de garantía y seguridad». En 1933 BANESTO sigue quejándose de la «inactividad manifiesta de la industria, del comercio y de los negocios en general», pero insiste en que se actúa «con juiciosa pruden. cia»; BUR reconocerá haber «intensificado, si cabe, las normas de previsión y prudencia con que hemos procedido en todo momento», y BSAB destaca que ha actuado con ala suavidad de trato que ha permitido la rigidez de las normas bancarias». Al año siguiente, 1934, todas las entidades vuelven a insistir en las medidas de precaución que han adoptado. Sólo en 1935 se percibe en las sobrias Memorias de los bancos un nuevo clima de optimismo. Para BANES. TO en ese año hubo «resurgir de los negocios»; para BUR, «una exacta realización de los pronósticos favorables»; para $\mathrm{BSAB}$, «un conjunto de factores hacen cada momento más floreciente y firme nuestra Entidad»; para $\mathrm{BB}$, el ejercicio fue «satisfactorio», relacionando el abaratamiento del dinero con la mejora de la situación de la Bolsa. Paralelamente, desaparece toda alusión a la necesaria ortodoxia de las prácticas bancarias.

Asi, parece confirmarse, como prevé el modelo, que ante la situación de crisis económica hubiera un notable incremento en los Costes de Intermediación Crediticia (CIC), que en ausencia de mecanismos operativos que pudieran contrarrestarlo tenderia a favorecer la aparición del racionamiento del crédito y el descenso del volumen total de operaciones crediticias. Por otra parte, esto es coherente con el hecho de que, desde el lado de la demanda, la revista Economía Española, órgano de expresión de la Unión Económica (que fue el eje de las organizaciones patronales durante la Segunda República), manifestara una continua postura crítica frente a los altos tipos de interés y la restricción crediticia. Por ejemplo, Mariano Marfil, su director, denunciaria en el curso de una conferencia celebrada el 18 de diciembre de 1933 que

«no puede existir la inflación crediticia cuando existen más de 3.000 millones de pesetas en las cuentas corrientes bancarias en espera de inversión. No puede existir tampoco cuando la demanda del comercio y la industria, desde hace varios años, es la rebaja del tipo de descuento, porque son pocos los paises que tienen un tipo de interés tan elevado como el nuestrom 51 .

A una petición similar se habian unido el año anterior el propio secretario del Consejo Superior Bancario, Francisco Bernis, personalidades como el ex ministro Julio Wais y hasta el propio gobierno se habia mostrado partidario

st Economia Española, 1934, nùm. 19. 
de acceder. Por el contrario, el Servicio de Estudios del Banco de España se opuso rotundamente porque consideraba, de forma muy conservadora, que existia una "franca inflación de medios de pago" 52 . Al final, la rebaja de octubre de 1932 fue de sólo medio punto porcentual, pasando la tasa de descuento del 6,5 al 6 por 100 . Se necesitarian dos años más para rebajarla otro medio punto, y sólo en julio de 1935 alcanzaria el 5 por 100. En total, cuatro años para conseguir una exigua rebaja de 1,5 puntos, mientras las políticas de «dinero barato» se imponian en el mundo, sobre todo tras la celebración de la Conferencia Económica Mundial de Londres, en junio de 1933, y la publicación por J. M. Keynes en ese año de The Means to Prosperity. Como destaca un conocido Informe de la Sociedad de Naciones publicado en 1944,

«Después de 1930 se registra un cambio progresivo pero persistente en la opinión de los economistas. El nivel de precios sera mirado cada vez más como un criterio secundario de la estabilidad económica. El nivel de empleo y la renta nacional tienden a ser el criterio esencial. Ocurre lo mismo con los métodos: la politica del banco central, por si sola, fue entonces considerada como relativamente ineficaz, $y$ se ve aparecer todo un arsenal de armas destinadas a apoyar la política del crédito puro y simple para atenuar las depresiones o favorecer la salida de una depresión» 53 .

El propio Servicio de Estudios del Banco de España pareció reconocer sus errores en un tardio Informe de mayo de 1935, donde se ensalza «el progreso de la economia inglesa de los últimos años" atribuyéndolo a la aplicación del principio homeopático similia similibus curantur que parecía subyacer en la caida de la libra y la bajada de los tipos de interés ${ }^{54}$. Contemplado el proceso en su conjunto, no parece justificarse que la principal razón de la caída del crédito descanse sobre la falta de demanda.

Una de las razones mas importantes para mantener elevados los tipos de interés fue la política del tipo de cambio de la peseta que, desde 1932, quedó estabilizada de facto con el franco francés, siendo España uno de los pocos paises que aproximarian sus politicas monetarias a las del llamado «bloque oro» ${ }^{55}$. Sin embargo, podría existir una segunda razón para mantener altos los

\footnotetext{
52 Véase sobre este punto, España Bancaria, 1932, núm. 13, La Epoca, 4 de abril de 1932, y BESE. D. 6532.

"Sociedad de Naciones (1944), p. 261.

it Véase BESE D. 6449.

"Creado por Francia para defender la paridad de las divisas con el oro, el abloque oro" agrupó como socios a Francia, Bèlgica, Italia, Holanda, Polonia y Suiza, y como «simpatizantes». a España, Letonia, Lituania, Turquia y Danzing. Aunque en la práctica funciono con alguna flexibilidad, las restricciones monetarias autoimpuestas, sin correspondencia en otros paises, provo-
} 
tipos de interés y es la acumulación de una enorme cantidad de deuda pública que en 1935 llegaria a volúmenes próximos al 80 por 100 de la renta nacional ${ }^{\circ}$. Y esta seria, además, una nueva razón para hablar de la existencia de racionamiento de crédito en base a los indicadores de Jaffee antes señalados. El cuadro 7 nos muestra los cambios habidos en la composición de la inversión de la banca privada en algunos paises europeos entre 1929 y 1935. Se puede observar con bastante claridad que la inversión crediticia era considerablemente reducida antes de la crisis, por lo que la inversión en valores mobiliarios (fondos públicos en un 60 por 100 en 1929, y en un 70 por 100 en 1935) constituia un destino desproporcionado en la orientación inversora de la banca española; sin embargo, desde esa fecha la composición de los activos se inclinó todavia más, y con gran rapidez, hacia esta forma de inversión ${ }^{57}$. Por otro lado, aunque tanto el descuento de efectos comerciales como los préstamos tendieron a declinar, en la segunda columna del cuadro 7 se aprecia que el descuento lo hizo con más suavidad que los préstamos, por lo que cabria esperar un acortamiento del plazo de vencimiento medio de todas las operaciones crediticias. En base a ello, cabe pensar que dos de los indicadores de Jaffee recogidos en la Sección II tienen alguna significación en este caso.

Finalmente, es oportuno volver a recordar que el componente de la demanda agregada más afectado durante la recesión española fue la inversión (véase, de nuevo, el cuadro 2), por lo que el tercer indicador de Jaffee también parecería ajustarse a la situación descrita. Además, nada de lo expuesto es de extrañar si se tiene en cuenta que fenómenos similares se dieron en Francia, donde la ortodoxia de la politica monetaria llevó a criticar la carencia de una politica de «dinero barato» que animase la concesión de crédito y a apuntar que la competencia de los fondos públicos, remunerados a altos tipos de interés, hacía muy dificil la obtención de crédito por el sector privado ${ }^{58}$. Reciente-

\footnotetext{
caron tendencias deflacionistas que hacia 1936 se hicieron insostenibles y obligaron al abandono generalizado de esta politica. Véase Einzig (1935) para un planteamiento general, $y$ Wet y Taver nier (1975) para un detallado análisis del caso belga.

5h Una elaboración propia en base a datos de Deuda Pública en circulación (DP) de Comin (1989), p. 875, y de Renta Nacional (RN) de Alcaide (1976), nos da que el coeficiente DP/RN pasó del 68,6 por 100 en 1929 al 79,5 por 100 en 1935. Es más, con los datos de Renta Nacional del Consejo de Economia Nacional este coeficiente superaria el 100 por 100 desde 1933.

5: Otro dato significativo es que, según datos de un Memorandum del Ministerio de Hacienda 11961 ), p. 5, la banca pasó de absorber el 11,9 por 100 de la deuda pública en 1930 al 14,4 por 100 en 1934. mientras caia su nivel de pignoración del 6,5 por 100 en 1930 al 5,6 por 100 en 1934. Todo ello prueba evidente del interés de la banca por mantener en su cartera estos valores.

"Vease, por ejemplo, Baudin (1933), Ansiaux (1934) y Lewinsohn (1935).
} 
mente se ha insistido en la coexistencia de una excesiva liquidez y la caida del crédito en la banca francesa de la época ${ }^{59}$.

\section{CUADRO 7}

Evolución de la inversión bancaria en Europa 1929-1935

\begin{tabular}{|c|c|c|c|c|}
\hline \multirow{2}{*}{ Paises (1) } & \multicolumn{2}{|c|}{$\begin{array}{c}\text { Crédito/Activo (2) } \\
\text { (porcentaje) }\end{array}$} & \multicolumn{2}{|c|}{$\begin{array}{c}\text { Descuento/Crédito (2) } \\
\text { (porcentaje) }\end{array}$} \\
\hline & 1929 & 1935 & 1929 & 1935 \\
\hline Alemania & 75,23 & 67,16 & 29,33 & 43,44 \\
\hline Dinamarca $\ldots \ldots \ldots \ldots \ldots \ldots \ldots \ldots \ldots \ldots \ldots \ldots \ldots \ldots$ & 61,56 & $62,76 *$ & 21.58 & $21,38^{*}$ \\
\hline 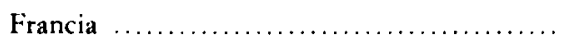 & 79,83 & 76,81 & 62,11 & 63.17 \\
\hline Hungria & 86,16 & 80,24 & 48,18 & 55,72 \\
\hline Inglaterra y Gales & 56,04 & 45,91 & 17,93 & 27,30 \\
\hline Italia $\ldots \ldots \ldots \ldots . . .$. & 47,03 & 44,63 & 70,62 & 80,29 \\
\hline Portugal & 51,08 & 48,33 & 57,24 & 66,57 \\
\hline$\ldots \ldots \ldots \ldots \ldots \ldots \ldots \ldots$ & 78,52 & 81,79 & 12.79 & 5.27 \\
\hline España ............. & 34,37 & 26,35 & 42,47 & 48,57 \\
\hline
\end{tabular}

Notas: * Es 1936. (1) Se trata de muestras de bancos muy amplias, con excepción de la francesa ( 8 bancos) y de la alemana (sólo grandes bancos de Berlín). (2) Crédito = Descuento + Préstamos.

Fuente: SDN (1942), Apendice, y Martin Aceña (1985a y 1985b).

\section{CONCLUSIONES}

El presente trabajo es un intento de dar una explicación a la fuerte caida del componente de inversión de la demanda agregada durante la coyuntura española que abarca la primera mitad de la década de 1930. Siguiendo un modelo teórico que empieza a conseguir buenos resultados, se argumenta que la evolución del multiplicador del crédito fue mucho más negativa que la del multiplicador monetario, por lo que deberemos estudiar con cierto cuidado las variables crediticias si queremos caracterizar adecuadamente el comportamiento global de los factores monetarios.

Hemos encontrado que tras la feliz intervención del Banco de España

59 Bouvier (1984). 
como prestamista de último recurso en 1931 , la situación monetaria entre 1932 y 1935 estuvo marcada por la ortodoxia monetaria, y no parece correcto generalizar sobre todo el periodo a partir de aquel primer episodio. En este sentido, hemos probado que los tipos de interés reales resultaron en términos internacionales muy elevados desde 1932.

Los altos tipos de interés no se manifestaron en una mayor oferta de crédito, pues los bancos percibieron el empeoramiento de la coyuntura económica y aumentaron los Costes de Intermediación Crediticia (CIC), que en España, dado el atraso operativo del sistema financiero, eran presumiblemente muy elevados. De este modo, se acortó el plazo de vencimiento de las operaciones crediticias (cayó menos el descuento comercial que el préstamo), y activos de riesgo reducido (aunque no exentos) como los fondos públicos fueron más demandados por la banca privada. Todo ello tiende a señalar la presencia de la restricción o el racionamiento en la oferta de crédito, aunque hay que advertir que los instrumentos utilizados (los indicadores indirectos de Jaffee) sólo constituyen una primera aproximación.

En definitiva, hemos encontrado nuevas razones para estar de acuerdo con los análisis pioneros de Sardá y sus seguidores, que ya resaltaron el carácter depresivo y procíclico de los factores monetarios durante la Segunda República, aunque no dudamos en advertir que toda la investigación requiere una mayor profundización que sólo será posible con la esperada apertura de los archivos de la banca privada española.

\section{BIBLIOGRAFIA}

\section{Fuentes no impresas}

I.1. Archivo Histórico del Banco de España. Dirección General de Sucursales

- Leg. 2248. Informe sobre el Banco Nacional Agrario.

I.2. Archivo Histórico del Banco de España. Sección Banca Privada

- Cajas 58-61. Registro de Bancos y Banqueros. Peticiones denegadas.

- Caja 63. Bancos inscritos en la Comisaria Regia de la Banca Privada y sus variaciones.

- Caja 153. Junta Consultiva de Cajas de Ahorros. Actas de las sesiones, 1931-1942. Actas del Consejo General del Banco de España (A.G.G.B.E.), 1930-1935.

I.3. Archivo del Servicio de Estudios del Banco de España

- D. 6449. La economia inglesa después de la caida de la libra. 
D. 6532. Informe elevado al Excmo. Sr. Ministro de Hacienda evacuando la consulta dirigida al Banco de Espana acerca de la conveniencia y oportunidad de alte. ración del tipo oficial de descuento (1932).

\section{Fuentes impresas}

II.1. Diarios y revistas

El Sol, La Epoca, Bancario, Economía Española, España Bancaria, Revista de Economia y Hacienda, España Económica y Financiera.

\section{I.2. Libros y articulos}

Alcaide, J. (1976): «Una revisión urgente de la serie de Renta Nacional espanola en el siglo XX», en Datos básicos de la historia financiera de España. 1850-1975. Madrid, Insti. tuto de Estudios Fiscales, pp. 1127-1150.

Alderoft, D. H. (1970): «The Impact of British Monetary Policy, 1919-1939», en Revue Internationale d' Histoire de la Banque, vol. 3.

Álvark\% Ll.ANo, R., y Anirkt; J. M. (1982): «Una historia de la banca privada en Españan, en Situación, núm. 1982/3.

Ansialix, M. (1934): L'inflation du crédit et la prevention des crises, Paris.

Asociacion Española de la Banca det. Centro de Espania: Memorias.

Batc.l.ts, A. (1971): Crisis económica y agitación social en Cataluña (1930-1936), Barcelona, Ariel.

Baldin, L. (1933): Le Crédit, Paris.

Banco de BILBAO: Memorias, 1930-1935.

Banco Espanol de (kedtu: Memorias, 1930-1935.

Banco de Sabadell: Memorias, 1930-1935.

Baveo Urqu'jo: Memorias, 1930-1935.

BELIORD, N. (1979): «El sistema bancario durante la Dictadura de Primo de Rivera», en Cuadernos Económicos de Información Comercial Española, núm. 10, pp. 227-266.

Briknanke, B. (1983): «Non Monetary Effects of the Financial Crisis in the Propagation of the (ireat Depression", en American Economic Review, num. 73, pp. 257-277.

Bernankf, B., y Blinder, A. S. (1988): «Credit, Money and the Aggregate Demand», en American Economic Review, vol. 78, num. 2, pp. 435-440.

Bl.INDER, A. S. (1987): «Credit Rationing and Effective Supply Failures», en The Economic Journal, vol. 97, núm. 386, pp. 327.353.

Bouvifr, J. (1984): "The French Banks, Inflation, and the Economic Crisis, 1919.1939», en Journal of European Economic History, vol. 13, num. 2, pp. 34-80.

Brunner, K., y Mritzer. A. H. (1988): «Money and Credit in the Monetary Transmission Process», en American Economic Review, vol. 78, num. 2, pp. 446.452.

Cagigal, M. (1922): Cámaras de compensación bancaria, Madrid.

Carreras, A. (1985): «Gasto nacional bruto y formación de capital en España, 1849. 1958: primer ensayo de estimación», en Martin Acena, P., y Prados dE la Escosura, L. (eds.): La nueva bistoria económica en España, Madrid, Tecnos, pp. 17.51.

Cakreras, A. (coord.) (1989): Estadisticas Históricas de España. Siglos XIX y XX, Banco Exterior, Madrid. 
CAssLs, S. (1984): «The Long Life of the Financial Institutions Set Up in the Thirties», en Journal of European Economic Histom, vol. 13, núm. 2.

ComiN, F. (1988): Hacienda y economía en la España contemporánea (1800-1936), Madrid, Instituto de Estudios Fiscales.

Conitt Interventok dei Mercado Bursatil de Barcfiona: Informes, Barcelona.

Conslo Supreror Bavearo (1930): Informo sobre las Cámaras de Compensación en el ex iranjero, Madrid.

— (1954): Los bancos en la postguerra, ¿vuelta a la normalidad? Madrid.

Department of Overseas Tradi: Economic Conditions in Spain. Annual Report.

Ec;U11)AZ', F. (1978): Intervención monetaria y control de cambios en España, 1900-1977. Madrid, IC.E-Libros

EIw/G, I'. (1935): World Finance, 1914-1935, Nueva York, Macmillan.

FonviEs, J. I. (1983): "Politica y ahorro popular durante la Segunda República», en Información Comercial Española, núm. 595.

Gotosmiru, R. (1983): The Financial Development of India, Japan, and the United States, Yale University Press.

Hernasifz Axidred, J. (1980): Depresión cconómica en Fspaña, 1925-1934, Madrid, Instituto de Estudios Fiscales.

- (1986): España y la crisis de 1929, Madrid, Espasa-Calpe.

Homit, S., y SiLla, R. (1991): A Histon of Interest Rates, Rutgers University Press.

JaffF, D. M., y Momlcilin, F. (1969): «A Theory and Test of Credit Rationing", en American Economic Reticu; vol. 59, num. 5, pp. 850-873.

JAFFE, D. M. (1971): Credit Rationing and the Commercial Loan Market, Nueva York, John Wiley \& Sons.

JAfFer, D. M., y Russcl... T11. (1976): «Imperfect Information, Uncertainty, and Credit Rationing", en The Quarterly Journal of Economics, vol. 99, num. 4, pp. 651-667.

Jafrli:, D. M. (1987): “Credit Rationing», en The New Palgrave. A Dictionary of Economics, vol. 1, Londres, Macmillan.

KF.Ton, W. 1 1979): Equilibrium Credit Rationing Nueva York, Garland Press.

Ktines, J. M. 119331: The Means to Prosperity, Londres.

Kindi.tibrol.k, CH. P. (1984; 1988): Historia financiera de Europa, Barcelona, Critica.

LewixsoH:, R. (1935): Historia de la crisis, 1929-1934, Madrid.

Liobr.RA, G. (1932): La vigilancia del crédito bancario, Lérida.

Martin Acresa, P. (1984): La politica monctaria en España, 1919-1935, Madrid, Instituto de Estudios Fiscales.

- (1985a): "Desarrollo y modernización del sistema financiero, 1844-1935", en Saxchiz-AlbokNoz. N. (ed.): La modernización económica de España, 1830-1930. Madrid, pp. $121 \cdot 146$.

Martin Aceñ P. (1985b): «La cantidad de dinero en España, 1900-1935», en Fstudios de' Historia Lonómica, núm. 12, Banco de España.

Ministerio di: Trabalo (1942): Boletín Estadistico. Número Extraordinario, Madrid.

Ministerio de: HACI:NIDA (1961): Memorándum sobre el sistema bancario y crediticio e informes sobre el mismo, Madrid.

Mitchtil., B. R. (1975): European Historial Statistics, 1750-1970). Londres, Macmillan.

MuNo\%, J. (1978): «La expansión bancaria entre 1919 y 1926: la formación de una banca nacional», en Cuadernos Económicos de ICE, núm. 6, pp. 98-162. 
Nadal, J. y Fontana, J. (1978): «España, 1914-1970», en Cipolla, C. M. (ed.): Historia económica de Europa, Madrid, Ariel.

PALAFOX. J. (1980): «La gran depresión de los años treinta y la crisis industrial españolaw, en Investigaciones Económicas, num. 11, pp. 5-46.

- (1991): Atraso económico y democracia. La Segunda República y la economía española, 1892-1936, Barcelona, Critica.

Paris Ecunlaz, H. (1965): El desarrollo económico español, 1906-1964, Madrid.

Polo, Y. 1988): Desarrollo de nuevos productos: aplicaciones a la economía española, Prensas Universitarias de Zaragoza.

Prados de la Escosura, L. (1988): De Imperio a Nación, Madrid, Alianza.

SARDA. J. (1970): «El Banco de España, 1931-1962», en El Banco de España. Una bistoria económica, Banco de España.

SDN (Sociéte des Nations) (1937): Statistical Yearbook, Ginebra.

SDN (1942): Money and Banking 1940-42, Ginebra.

SDN (1944): L'experience monétaire intermationale. Enseignements de la période d'entre les deux guerres, Ginebra.

Stiglit/, J. E., y Wf.ISs, A. (1981): «Credit Rationing in Markets with Imperfect Information», en American Economic Review, vol. 71, num. 3, pp. 393.411.

TFNA, A. (1989): «Comercio exterior», en Carreras, A. (coord.), pp. 327-363.

Toktella, G., y Palal:ox, J. (1982): «Banca e industria en España, 1918-1936», en Investigaciones económicas, núm. 20, pp. 33-64.

Torteilla, G., y Jimenez, J. C. (1986): Historia del Banco de Crédito Industrial, Madrid, Alianza/BCI.

UNITED Nations (1952): Statistical Yearbook, Nueva York.

VFGA, J. L. (1992): "El papel del crédito en el mecanismo de transmisión monetaria», en Estudios Económicos, núm. 48, Banco de España-Servicio de Estudios.

Vel.ARIE, J. (1973): Política económica de la Dictadura, Madrid, Guadiana, 2." ed.

WE, H. van der y TAVFrnier, K. (1975): La Banque Nationale de Belgique et l'bistoire monétaire entre les deux guerres mondiales, B.N.B., Bruselas. 